\title{
Large biological cycle duration in patients with respiratory organs disorders
}

\author{
Iryna Savenkova ${ }^{1}$, Mykola Didukh$^{1}$, Liudmyla Mukhina ${ }^{1}$, Iryna Litvinenko ${ }^{1}$
}

\begin{abstract}
Objective: In recent times, the need for an integrated approach to prognosing the course of non-infectious diseases of the respiratory organs became especially relevant. The complexity of the investigated phenomena has proved the unreason ability of simplified causative explanatory models of the respiratory organs psychosomatic disorders. Objective study of the disorders prognosing mechanisms is possible only taking into account the multidimensionality of the investigated phenomena. The purpose of the study is to analyze the frequency of exacerbation of the upper respiratory tract organs in the ontogenetic scan.

Method: The method of chronometric testing with the purpose of determining the subjective time unit of a pulmonologic patient (using an electronic chronoscope); methods of mathematical statistics: descriptive statistics, methods of averages, percentile statistics, comparison of mean values using the Student's t-test.

Results: The results of the experimental study suggest that for the majority of surveyed patients with the respiratory organs non-infectious diseases it is common that the clinical manifestations of the disease not only coincide with the ends of the long cycle quarters and with the end of the cycle itself, but also begin to repeat with a periodicity of $1 / 4 \mathrm{C}, 1 / 2 \mathrm{C}, 1 / 16 \mathrm{C}, 3 / 4 \mathrm{C}$ depending on a typological group affiliation.

Conclusion: The article presents the study results of the manifestation of "C-metrics" on the example of the upper respiratory tract disorders during periods of exacerbation of the disease. It has been experimentally proved that the point of the least resistance is most affected at the end of a large biological cycle or at the ends of this cycle quarters.
\end{abstract}

Keywords: large biological cycle, disorder C-metrics, psychosomatic disease, subjective time unit, lowest resistance point

\section{INTRODUCTION}

Psychosomatic disorders have been under the lens of medical psychology for more than a decade. The level of demands that the contemporary life puts to a person has grown. Modern cultural, economic and social transformations require a person to mobilize extraordinary cognitive, emotional and personal resources, as well as to be constantly ready to solve daily problems.

Modern medicine officially came to the recognition of the fact that all the causes of psychosomatic disorders should be sought not in the external, but in the internal processes of the individual, taking into account the manifestation of the latter in the individual's behavior. P. Henningsen, S. Zipfel, H. Sattel, F. Creed present the results of the study concerning the management of functional somatic syndromes and bodily disorders (15). Scientists focus on the biopsychosocial approach, suggesting an etiological model of managing functional somatic syndromes. This model includes, first of all, the psychotherapeutic effect on the leading emotions, which contributes to the effective treatment of such patients.

Scientists, studying the factors that influence the disease response formation, emphasize the fact that the individual psychological features are more informative for the prediction of personal reactions to the disease than the clinical evaluation of the severity of the disease. J. Wendt, A. Hamm, C. Pane-Farre used psychosomatic approach in the treatment of cardiovascular diseases, indicating the role of anxiety in the regulation of cardiac vagal tone (26). Researches of the scientists allow to come to the conclusion that patients with low vagal tone may need motivation support during therapy. This will reduce anxiety and improve the effectiveness of treatment.

1 Sukhomlynskyi Mykolaiv National University, Mykolaiv, Ukraine.

Received: 25 Jul 2018, Accepted: 30 Sep 2018
Correspondence: Iryna I. Savenkova

Nikol's'ka St, 24, Sukhomlynskyi Mykolaiv National University, Mykolaiv, 54000, Ukraine.

(C) 2018 by the authors; licensee Modestum Ltd., UK. This article is an open access article distributed under the terms and conditions of the Creative Commons Attribution License (http://creativecommons.org/licenses/by/4.0/). 
It is the individual psychological peculiarities of the person that determine, in our opinion, (7), a somatic disorder certain symptom, which include psychosomatic disorders. We turned to the consideration of this issue, taking into account the individual peculiarities of the dynamic experience of time (12) and the data of the generalized profiles on this category, and attempted to determine the criteria of the prevailing diseases typology.

Possibility of early prediction of a disease course makes it possible to prevent the exacerbation of this disorder. Unfortunately, until now in pulmonology it is rarely possible to use the most rational etiologic principle of treatment, however timely and effective psychological preventive measures of impact can in a number of cases significantly change the prognosis. The urgency and unresolved problem of respiratory diseases timely diagnosis led us to a chronopsychological study.

According to the data of scientific literature $(13,14)$, the type of subjective time perception or time orientation is one of the objective indicators of the dynamic properties of the individual's psyche, reflecting the consistent process of change that happens to a person throughout her life. Consequently, the changes occurring in the individual's body, both psychic and somatic, are closely related to the time aspect.

B. Tsukanov stressed that the life of the individual from birth to death can be broken into a number of periods (25). Multi-day, multi-month, and multi-year cycles (2). The scientist distinguished the turning points in human life that is a certain age in which "psychological fractures" occur and called them key points. Thus, the discrete counting of individual time leads to the fact that at the level of subjective experiences and behavioral manifestations the human life is uneven, that is, during the life there are clearly distinguished periods in the middle of which a person is in the optimal psychosomatic state, and at the beginning and at the end - at a minimum of his capabilities. Such periods have been called the large biological cycles. The duration of one cycle for the average subject is 7.65 years (3). The inter-individual range of oscillations in accordance to the values of " $\tau$-types" is from 6.5 to 9.5 years. Today we are confident that on the scale of large biological cycles the age-related development of psyche is happening, the activity success fluctuation, the chronic non-infectious disorders exacerbation, as well as the psychosomatic crisis of personality $(6,19)$.

The timely prevention of psychosomatic disorder conducted twice a year (spring-autumn) with the use of the dispensary surveillance developed treatment methods does not prevent the exacerbation of the disease in individuals suffering from these disorders. The medical practice of the author shows that, despite preventive measures, patients experience exacerbation of the disease in different seasons (18). This means that preventive measures were not carried out in a timely manner. This untimely disorder prevention is explained by the fact that medicine can not predict exacerbation of psychosomatic illness (9). In our opinion, the reason for this phenomenon in medicine is the absence of the principle of an individual approach to the treatment and prevention of the disease, which requires a comprehensive consideration of the psychological characteristics of each individual (20). This principle is not accidentally laid as the cornerstone of the solution of an important problem of modern medicine, that is, the pulmonary diseases course prognosis.

The absence of concepts interpretations such as "psychosomatic factor of time," "psychosomatic C-metric" of diseases associated with chronopsychological prediction of the course of psychosomatic diseases in the scientific literature, required their refinement.

We turned to the consideration of this issue, taking into account the individual's life biological cycle duration (10). Namely, the duration ratio of the individual's life biological cycle and the pulmonological disease exacerbation periodicity.

A sufficiently clear age-related repeatability in the boundary nervous-psychiatric disorders was firstly pointed out by O. Kerbikov (17).

Muriel Thoby-Brisson's research prove the role of adult generation neurogenic mechanisms during the prenatal period (24). At the same time, the scientist shows that early rhythmogenesis during embryonic development is due to the features of the neurogenic mechanisms of their generation.

The studies of Savenkova (22) also revealed a marked periodicity of the cardiovascular disorders manifestation. Repeated exacerbation of the disease observed concurrently with other psychosomatic disorders causes the chronization of the pathological process. Thus, in medicine the exacerbation of glomerulonephritis (the lesion of glomeruli and renal tubules) within five years after the disorder is considered possible. This is the so-called period of remission (attenuation) of the disease. And the answers to the questions: why exactly there is an exacerbation of the disease and when it will take place in the individual patient, does not exist in medicine.

In this respect, we tried to compare the human ontogenetic development periodization and the exacerbation periods of pulmonary diseases by analyzing scientific sources and experimental research. 
The congenital genotypic predisposition to the development of respiratory diseases is indicated in the studies by Andrushchenko, Goncharov, Dosenko (1). Scientists conducted a study of workers in the hazardous industry who had a risk of developing pulmonary diseases. The results of the study show that there are groups of people who are genotypically predisposed to bronchopulmonary pathology. Thus, confirm the presence of "the place of least resistance" in these categories of people.

To explain the diseases periodicity heterochronism in people suffering from the respiratory system chronic diseases, it was suggested that their origin coincides either with the end of a prolonged large biological cycle, or with the end of its long quarters. For each group of patients was calculated the average age from the date of birth to the beginning of the disease, in the value of a large biological cycle and converted into years.

The study hypothesis is stated as the isolation of duration of the human life biological cycle in person which suffers from the respiratory organs psychosomatic disorder, will provide an accurate prognosis for the disorder exacerbation and its timely prevention.

The purpose of the study is to analyze the exacerbation frequency of the respiratory system disorders in an ontogenetic scan, taking into account the individual's life biological cycle duration.

We set the task: to explore the "C-metrics" manifestation on the example of pulmonological disorders in different disease periods (exacerbation, reconvalescence and remission).

\section{MATERIALS AND METHODS}

Participants. 960 patients with respiratory diseases were screened. Among them 750 patients suffered for noninfectious rhinopharyngitis, and 210 patients experienced recurrent laryngotracheitis.

Organization of research.

A questionnaire was filled out for each patient determining the following:

1) the age of the person (indicating the quantity of years and months at the moment of the survey);

2) number, month, year of birth;

3) the type of psychosomatic disorder.

On the basis of the obtained chronometry results, a table was constructed with the definition of the individual's time $\tau$-subjective. For each patient who was examined with the help of a chronometric probe method (9), the " $\tau$-type" was identified, using the classic method of reproducing time intervals $t_{0}=2,3,4,5 \mathrm{~s}$, set by the researcher and reproduced by the subjects using an electronic chronoscope to accuracy within $0.001 \mathrm{~s}$. After the sound signal, each examinee was asked to reproduce the duration he experienced. The duration was limited to two signals - "start" and "finish" in the form of sound that occurs when triggering and stopping the chronoscope. The subjects were asked to reproduce the intervals that were set up on this chronoscope.

\section{RESULTS}

Statistical analysis. The individual value of the " $\tau$-type" was calculated according to the formula for each proposed interval:

$$
\tau=\frac{\sum t_{s}}{\sum t_{o}}
$$

where $t_{o}$ is the duration given by the experimenter, and $t_{s}$ is the duration reproduced by the examinee.

The reproduction of each time interval was repeated five times, and then the average value of the actual unit of time of each subject was counted.

This relation was first proposed by Erenwald to characterize the individual results of the reproduction method (5). But if Erenwald, and then other authors, used this relation as an immeasurable coefficient, Tsukanov (25) attributes it the semantic meaning of the individual subjective time unit. The actual given interval $t_{o}$ is the duration experienced in one section of the "subjective time arrow," and the $t_{s}$ duration is reproduced in its second section, in relation to which $t_{o}$ is already in the past. Ergo, Tsukanov comes to the conclusion that the given $t_{o}$ interval in the situation of intense waiting breaks down to a certain number of the individual's subjective units, and the restored $t_{s}$ duration consists of this number (25). This method of reproducing the duration to determine the " $\tau$-type" allows us to solve the problem of the psychosomatic diseases course chronopsychological prediction. 
Table 1: Estimated and statistical age of the beginning of the noninfectious rhinopharyngitis exacerbation

\begin{tabular}{|c|c|c|c|c|c|c|c|c|}
\hline Group & 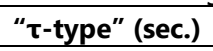 & C & & cles $(y$ & & Statistical age of patients & $\boldsymbol{\sigma}$ & $\mathbf{t}$ \\
\hline \multirow{2}{*}{$\begin{array}{c}\text { Men } \\
\text { (130ind.) }\end{array}$} & \multirow{2}{*}{$0.7 \leq \tau \leq 0.72$} & \multirow{2}{*}{6.0} & $5 C$ & $7 C$ & $9 \mathrm{C}$ & \multirow{2}{*}{$35-45-75$} & \multirow{2}{*}{1.6} & \multirow{4}{*}{$\begin{array}{c}0.001 \\
*\end{array}$} \\
\hline & & & 32 & 45 & 75 & & & \\
\hline \multirow{2}{*}{$\begin{array}{l}\text { Women } \\
\text { (136ind.) }\end{array}$} & \multirow{2}{*}{$0.7 \leq \tau \leq 0.72$} & \multirow{2}{*}{6.0} & $5 \mathrm{C}$ & $61 / 2 C$ & $8 C$ & \multirow{2}{*}{$32-40-50$} & \multirow{2}{*}{1.2} & \\
\hline & & & 32 & 40 & 50 & & & \\
\hline \multirow{2}{*}{$\begin{array}{c}\text { Men } \\
\text { (121ind.) }\end{array}$} & \multirow{2}{*}{$0.73 \leq \tau \leq 0.75$} & \multirow{2}{*}{6.29} & $7 \mathrm{C}$ & $73 / 4 \mathrm{C}$ & $81 / 2 C$ & \multirow{2}{*}{$42-44-51$} & \multirow{2}{*}{1.4} & \multirow{4}{*}{$\begin{array}{c}0.001 \\
*\end{array}$} \\
\hline & & & 42 & 44 & 51 & & & \\
\hline \multirow{2}{*}{$\begin{array}{l}\text { Women } \\
\text { (125ind.) }\end{array}$} & \multirow{2}{*}{$0.73 \leq \tau \leq 0.75$} & \multirow{2}{*}{6.29} & $71 / 4 \mathrm{C}$ & $8 \mathrm{C}$ & $93 / 4 C$ & \multirow{2}{*}{$43-51-62$} & \multirow{2}{*}{1.2} & \\
\hline & & & 43 & 51 & 50 & & & \\
\hline \multirow{2}{*}{$\begin{array}{c}\text { Men } \\
\text { (128ind.) }\end{array}$} & \multirow{2}{*}{$0.76 \leq \tau \leq 0.79$} & \multirow{2}{*}{6.64} & $43 / 4 \mathrm{C}$ & $6 \mathrm{C}$ & $71 / 4 \mathrm{C}$ & \multirow{2}{*}{$33-38-50$} & \multirow{2}{*}{1.5} & \multirow{4}{*}{$\begin{array}{c}0.01 \\
*\end{array}$} \\
\hline & & & 33 & 38 & 50 & & & \\
\hline \multirow{2}{*}{$\begin{array}{l}\text { Women } \\
\text { (100ind.) }\end{array}$} & \multirow{2}{*}{$0.76 \leq \tau \leq 0.79$} & \multirow{2}{*}{6.64} & $6 \mathrm{C}$ & $61 / 2 C$ & $7 C$ & \multirow{2}{*}{$40-45-48$} & \multirow{2}{*}{1.4} & \\
\hline & & & 40 & 45 & 48 & & & \\
\hline
\end{tabular}

NOTE: * $p<0.05$

By the law of experiencing time by subject (25), the large biological cycle of the individual is determined by the formula:

$$
C=8.5 \tau \text { (years) }
$$

where $\tau$ is the subjective time unit of the individual. This unit acts as a "step", which measures the lifetime of each individual from the moment of birth.

Was conducted the statistical analysis of the age of patients with non-infectious rhinopharyngitis, in which their subjective time unit is in the range of $0,72 \mathrm{~s} \leq \tau \leq 0,78 \mathrm{~s}$.

In these groups of patients (92\% of the total number in the experimental sampling) there is a "C-periodicity" exacerbation of the disease, which coincides with $1 / 2 C, 3 / 4 C, C, 1 \frac{114}{4}, 1 \frac{1}{2} C$. The estimated and statistical years of the surveyed individuals with respiratory diseases in the period of exacerbation are summarized in Table 1.

We provide individual data for some patients from a group of individuals suffering from chronic pulmonary disorders. They have "C-periodicity" of the disease manifestation.

Patient V. ( $\tau=0.71 \mathrm{~s} \mathrm{C}=5.96$ p.). Date of birth: 12.08 .1966 .

At the dispensary record in the clinic from 17 years 8 months to 2 days with the diagnosis: non-infectious rhinopharyngitis.

Second exacerbation - 29 years 8 months 3 days.

Third exacerbation - 41 years 7 months 14 days.

Estimated age of first exacerbation: $3 C$.

Estimated age of second exacerbation: $5 \mathrm{C}$

Estimated age of the third exacerbation: 7C.

Frequency of exacerbation: $2 \mathrm{C}$.

Patient T. ( $\tau=0.77$ s C $=6.48$ p.). Date of birth: July 20, 1968

He got into a therapeutic department with a diagnosis: non-infectious rhinopharyngitis, a period of exacerbation at the age of 42 years 8 days.

Estimated age: $61 / 2 \mathrm{C}$.

First exacerbation - 38 years 8 months 16 days.

Estimated age: 6C.

Frequency of exacerbation: $1 / 2 \mathrm{C}$.

The third disease exacerbation was at the age of 45 years 3 months 19 days. The following exacerbations of the disease is expected with a period of $1 / 2$ C. By this time, it is necessary to plan psychoprophylaxis concerning the disease exacerbation and prevent the further development of the disease.

Among the patients suffering from recurrent laryngotracheitis, 230 patients were examined. The subjective time unit of these individuals was determined in the range: $0.79 \mathrm{~s} \leq \tau \leq 0.86 \mathrm{~s}$, indicating a particular localization of recurrent laryngotracheitis in the continuous spectrum of " $\tau$-types".

The results of the study data relating to the age of patients with chronic respiratory diseases were statistically processed in the value of a large biological cycle and translated into years. In these groups of patients suffering from chronic respiratory disorders, there is a "C-periodicity" of the disease exacerbation, which coincides with 51/4C, 71/2C, $93 / 4$ C. Estimated and statistic age of surveyed patients with respiratory diseases in the period of exacerbation are summarized in Table 2. 
Table 2: Estimated and statistical age of the beginning of the recurrent laryngotracheitis exacerbation

\begin{tabular}{|c|c|c|c|c|c|c|c|c|}
\hline Group & „т-type" (sec.) & C & & es (ye & & Statistical age of patients & $\boldsymbol{\sigma}$ & $\mathbf{t}$ \\
\hline \multirow{2}{*}{$\begin{array}{c}\text { Men } \\
\text { (35ind.) }\end{array}$} & \multirow{2}{*}{$0.79<\tau \leq 0.82$} & \multirow{2}{*}{6.8} & $5 C$ & $7 C$ & $9 C$ & \multirow{2}{*}{$36-50-64$} & \multirow{2}{*}{1.2} & \multirow{4}{*}{$0.001^{*}$} \\
\hline & & & 34.5 & 48.3 & 62.1 & & & \\
\hline \multirow{2}{*}{$\begin{array}{l}\text { Women } \\
\text { (40ind.) }\end{array}$} & \multirow{2}{*}{$0.79<\tau \leq 0.82$} & \multirow{2}{*}{6.8} & $5 \mathrm{C}$ & $61 / 2 C$ & $8 \mathrm{C}$ & \multirow{2}{*}{$36-50-57$} & \multirow{2}{*}{1.2} & \\
\hline & & & 34.5 & 48.4 & 55.2 & & & \\
\hline \multirow{2}{*}{$\begin{array}{c}\text { Men } \\
\text { (32ind.) }\end{array}$} & \multirow{2}{*}{$0.82<\tau \leq 0.84$} & \multirow{2}{*}{7.1} & $7 C$ & $73 / 4 \mathrm{C}$ & $81 / 2 C$ & \multirow{2}{*}{$51-57-61$} & \multirow{2}{*}{1.3} & \multirow{4}{*}{$0.001^{*}$} \\
\hline & & & 49 & 55 & 59.5 & & & \\
\hline \multirow{2}{*}{$\begin{array}{l}\text { Women } \\
\text { (37ind.) }\end{array}$} & \multirow{2}{*}{$0.82<\tau \leq 0.84$} & \multirow{2}{*}{7.2} & $71 / 4 C$ & $8 \mathrm{C}$ & $93 / 4 C$ & \multirow{2}{*}{$51-58-70$} & \multirow{2}{*}{1.2} & \\
\hline & & & 49 & 56 & 68.3 & & & \\
\hline \multirow{2}{*}{$\begin{array}{c}\text { Men } \\
\text { (45ind.) }\end{array}$} & \multirow{2}{*}{$0.84<\tau \leq 0.86$} & \multirow{2}{*}{7.2} & $43 / 4 C$ & $6 \mathrm{C}$ & $71 / 4 \mathrm{C}$ & \multirow{2}{*}{$37-46-55$} & \multirow{2}{*}{1.5} & \multirow{4}{*}{$0.01^{*}$} \\
\hline & & & 34.7 & 43.8 & 53 & & & \\
\hline \multirow{2}{*}{$\begin{array}{l}\text { Women } \\
\text { (41ind.) }\end{array}$} & \multirow{2}{*}{$0.84<\tau \leq 0.86$} & \multirow{2}{*}{7.1} & $6 \mathrm{C}$ & $61 / 2 C$ & $7 C$ & \multirow{2}{*}{$45-49-53$} & \multirow{2}{*}{1.2} & \\
\hline & & & 43.8 & 47.5 & 51 & & & \\
\hline
\end{tabular}

NOTE: ${ }^{\star} p<0.05$

We provide individual data of some patients from a group of suffering from chronic pulmonary disorders in the form of recurrent laryngotracheitis. The " $\mathrm{C}$-periodicity" of the disease manifestation is observed among these patients.

Patient C. ( $\tau=0.81 \mathrm{~s} \mathrm{C}=0.80$ p.). Date of birth: 15.07 .1956

He got into the hospital's therapeutic department at the age of 55 years 2 months 12 days with a diagnosis: recurrent laryngotracheitis.

From the disease anamnesis: the first exacerbation was at the age of 34 years 6 months.

Second exacerbation - at the age of 48 years 4 months 24 days.

Estimated age of the third exacerbation: $8 \mathrm{C}$.

Estimated age of second exacerbation: 61/2 S.

Estimated age of first exacerbation: $5 \mathrm{C}$.

Frequency of exacerbation: $1 / 2-1 \frac{1}{2} \mathrm{C}$.

Based on these periods of exacerbation of the disease, the doctor can predict and timely prevent the disease, thus preventing the exacerbation of the disease in each individual case.

\section{DISCUSSION}

In general, many researchers conduct the age-related periodization of human ontogenetic development and distinguish certain cycles and phases of somatic, sexual, neuropsychological and intellectual maturation. This we've found in the works of Fress (11) that deals with constitutional biology and anthropometry; Shnoll, who studied psychology of senior pupils (23), Birren (2) who researched age psychology and Brun (3) the representative of gerontopsychology. Elkin (6) points out that these cycles and phases of development are "the characteristics of time" and they can not be independent of the course of the individual's central biological clock. Taking into account the central clock movement continuity, Tsukanov (25) suggested that the transfer ratio of 1:4 is kept by individuals in the range of $0.8 \mathrm{~s} \leq \tau \leq 1.0 \mathrm{~s}$ when they experience multi-day, multi-month, and multi-year cycles. Based on a series of studies $(4,8)$, Tsukanov assumed that the transfer number remains unchanged, regardless of whether the individual is awake or asleep (25). Within these periods, some people undergo a gradual inversion of the temperature curves of the circadian cycle during the transition from the day phase to the night. This is noted in the writings by Shnol (23) and Fress (17). In Savenkova studies (22) it is shown that in individuals with hypertonic tendency through periods $T_{n=3}$ a sharp jump in blood pressure is observed. According to the scientist, a sharp difference in blood pressure, which coincides with the period $T_{n=3}$, can be evaluated as a peculiar mark of the "end-beginning" moment of the multi-year cycle in the time experienced by the subject.

For the medium group subject:

$\mathrm{T}_{\mathrm{n}=5}=1,92$ years $=2$ years, that is, the received biennial cycle, identified by Birren (2).

When $\mathrm{n}=6 \mathrm{~T}_{\mathrm{n}=6}=8,51 \tau$ (years).

This period was called the large biological cycle by Tsukanov (25).

Periodization of individual development is based on the fact that in the natural sciences, psychology, medicine and pedagogy accumulated "a huge fund of knowledge about the unevenness and heterochronism of growth and differentiation of tissues, bone and muscular system, various glands of the internal secretion, the central parts of the CNS. In detail known phenomena of heterochronous general somatic, sexual and neuro-mental maturation" (21). If the 
life of an individual consists of a number of cycles that change each other, will a large biological cycle in the periods of exacerbation, remission (attenuation) and reconvalescence (recovery) of psychosomatic disorders not manifest? By continuous observations of heterochronic changes in ontogeny, I.Savenkova (22) has discovered, that processes of somatic, sexual and neuro-mental maturation proceed rapidly, and the processes in period of maturity and aging are slowed down. Proceeding from the value of $C$ (a large biological cycle), B. Tsukanov showed that the infant period is continued $1 / 4 C$ (25). To reach the beginning of the childhood period, it is necessary to live $3 / 4 C$. Before the beginning of the puberty period, it is necessary to live half of the second large biological cycle, the maturity continues to $31 / 4 C$, and the late maturity lasts $31 / 2 \mathrm{C}$ according to the Birrren's age periodization period (2).

In our previous studies it was proved that in the range of $0.7 \mathrm{~s} \leq \tau \leq 0.8 \mathrm{~s}$ localized mostly groups of individuals in which pulmonologic diseases predominate. The obtained results of the study allowed to establish a system of interconnection and interdependence of the manifestation of psychosomatic diseases from the chronopsychological peculiarities of the subject, in particular, his time parameters during somatic disorders. Since these disorders belong to the type of "psychosomatic disorder" $(4,9)$, we statistically processed the age related data of patients with pulmonary disorders.

Scientific novelty of the study. The results of our survey suggest that in different individuals their dominant disease manifests itself with a certain "C-periodicity".

An analysis of the age of patients from the date of birth to the onset of the disease shows that the lowest resistance point is most affected at the end of a long, large biological cycle or its long quarters.

The majority of surveyed patients with pulmonary diseases are generally characterized by the fact that the clinical manifestations of the disease not only coincide with the end of a quarter of the long cycles and with their ends, but also start to repeat with a periodicity of $1 / 4 C, 1 / 2 C, 1 / 16 C, 3 / 4 C$, depending on the affiliation with the typological groups. The disease takes a chronic character, because it is not diagnosed in the early stages of ontogenesis.

\section{CONCLUSION}

Thus, the discrete counting of subjective time leads to the fact that at the level of subjective experiences and behavioral manifestations the human life flows unevenly, that is, during the life there are clearly distinguishable periods in the middle of which a person is in the optimal psychosomatic form, and in the beginning and at the end - at a minimum of their capabilities.

The perspectives of further scientific. In the future, it is promising to develop comprehensive medical-psychological prevention mechanisms of the respiratory organs disorders aimed at timely prevention of the disease exacerbation, taking into account the biological cycle of human life duration.

\section{REFERENCES}

1. Andrushchenko TA, Goncharov SV, Dosenko VE. Fiziologichnyi Zhurnal 2018;64(4):12-9. https://doi.org/10.15407/fz64.04.012

2. Birren JE. The psychology of ageing. Boston: Little, Brow Company 2014.

3. Brun R. General treatment of nevrosis. Springfield: Merriam-Webster 2016.

4. Desai G, Chaturvedi SK. Do Diagnostic Criteria for Psychosomatic Research Explain Diagnosis of Medically Unexplained Somatic Symptoms? Psychotherapy and Psychosomatic 2016;85:121-2. https://doi.org/10.1159/000441063 PMid:26807856

5. Ehrenwald H. Attempts to time perception of the unconscious ark. New York: Psychologie 2014.

6. Elkin DG. Experiencing time. Doctoral thesis. Odessa: ONU imeni I.I. Mecnikova 1945.

7. Elkelboom EM, Tak LM, Roest AM, Rosmalen JG. A systematic review and meta - analysis of the percentage of revised diagnoses in functional somatic symptoms. Journal of Psychosomatic Research 2016;88:60-7. https://doi.org/10.1016/j.jpsychores.2016.07.001 PMid:27455914

8. Fava GA, Cosci F, Sonino N. Current Psychosomatic Practice. Psychotherapy and Psychosomatics 2017;86:13-30. https://doi.org/10.1159/000448856 PMid:27884006

9. Fink P. Syndromes of bodily distress or functional somatic syndromes where are we heading. Journal of Psychosomatic Research 2017;97:127-30. https://doi.org/10.1016/j.jpsychores.2017.04.012 PMid:28606492 
10. Fraisse P. Psychology of Time: conditioning, perception, control, time estimation, concept of time. Basel: E. Reinhard 2015.

11. Fress P. Human adaptation to time. Moscow: Progress 1961.

12. Harchenko DM. Personal peculiarities of people with different alexithymic radical. Relevant problems in psychology 2016;8:127-30.

13. Harchenko DM. Psychosomatic disorders in humans with different behavioral activity types. Relevant problems in psychology 2015;4:284-90.

14. Harchenko DM. Anxiety in people with different alexithymic condition. Relevant problems in psychology 2015;7:157-9.

15. Henningsen P, Zipfel S, Sattel H, Creed F. Management of Functional Somatic Syndromes and Bodily Distress. Psychotherapy and Psychosomatics 2018;87(1):12-31. https://doi.org/10.1159/000484413 PMid:29306954

16. James W. The prinsiples of Psychology. Boston: Little, Brown Company 2016.

17. Kebrikov AV. About time perception. Moscow: Vysshaya shkola 2013.

18. Koffka K. Principles of Gestalt Psychology. Springfiel: Merriam-Webster 2015.

19. Kuhn TS. The structure of scientific revolutions. Frankfurt: Suhrkamp 2016.

20. Polunin OV. Psychological research of experiencing the present. Psychology and society 2013;4:138-43.

21. Polunin OV. Human experience of the time flow: experimental research. Kyiv: Hnozis 2014. PMCid:PMC4335981

22. Savenkova II. Differentiation of time characteristics in subjects with nephrological disorders. Relevant problems in psychology 2014;6:267-74.

23. Shnoll SE. Biological clock. Moscow: Mir 2014.

24. Thoby-Brisson M. Neural mechanisms for sigh generation during prenatal development. Journal of Neuropsychology 2018;120(3):1162-72.

25. Tsukanov BY. Time in human psyche. Odesa: Astroprint 2000.

26. Wendt J, Hamm A, Pane-Farre C. Pretreatment Cardiac Vagal Tone Predicts Dropout from and Residual Symptoms after Exposure Therapy in Patients with Panic Disorder and Agoraphobia. Psychotherapy and Psychosomatics 2018;87:187-9. https://doi.org/10.1159/000487599 PMid:29533952

$\diamond \diamond \diamond \diamond \diamond \diamond \diamond$

http://www.ejgm.co.uk 